\title{
CONF-950961--16
}

\section{THE EFFECT OF NEUTRON SPECTRUM ON THE MECHANICAL AND PHYSICAL PROPERTIES OF PURE COPPER AND COPPER ALLOYS}

\author{
S.A. Fabritsiev ${ }^{1}$, A.S. Pokrovsky ${ }^{2}$, S.J. Zinkle ${ }^{3}$, A.F. Rowcliffe ${ }^{3}$, D.J. Edwards ${ }^{4}$, \\ F.A. Garner ${ }^{4}$, V.A. Sandakov ${ }^{2}$, B.N. Singh ${ }^{5}$ and V.R. Barabash ${ }^{6}$. \\ ${ }^{1}$ D.V. Efremov Institute of Electrophysical Apparatus, 189631 St.Petersburg, Russia \\ ${ }^{2}$ Scientific Research Institute of Atomic Reactors, 433510 Dimitrovgrad, Russia \\ ${ }^{3}$ Oak Ridge National Laboratory, P.O. Box 2008, Oak Ridge, TN 37831-6376 USA \\ ${ }^{4}$ Pacific Northwest Laboratory, P.O. Box 999, Richland, WA 99352 USA \\ ${ }^{5}$ RIS $\varnothing$ National Laboratory, P.O. Box 49, DK-4000 Roskilde, Denmark \\ ${ }^{6}$ ITER Joint Central Team, Max-Planck Inst. fur Plasmaphysik, D-85748 Garching, Germany
}

\begin{abstract}
The electrical resistivity and tensile properties of copper and oxide dispersion strengthened (DS) copper alloys have been measured before and after fission neutron irradiation to damage levels of 0.5 to 5 displacements per atom (dpa) at $\sim 100$ to $400^{\circ} \mathrm{C}$. Some of the specimens were irradiated inside a $1.5 \mathrm{~mm} \mathrm{Cd}$ shroud in order to reduce the thermal neutron flux. The electrical resistivity data could be separated into two components, a solid transmutation component $\Delta \rho_{\mathrm{tr}}$ which was proportional to thermal neutron fluence and a radiation defect component $\Delta \rho_{\text {rd }}$ which was independent of displacement dose. The saturation value for $\Delta \rho_{\mathrm{rd}}$ was $\sim 1.2 \mathrm{n} \Omega-\mathrm{m}$ for pure copper and $\sim 1.6 \mathrm{n} \Omega$-m for the DS copper alloys irradiated at $100^{\circ} \mathrm{C}$ in positions with a fast-to-thermal neutron flux ratio of 5 . Considerable radiation hardening was observed in all specimens at irradiation temperatures below $200^{\circ} \mathrm{C}$. The yield strength was relatively insensitive to neutron spectrum in specimens strengthened by dispersoids or cold-working.
\end{abstract}

Key words: electrical resistivity, yield strength, copper alloys, radiation hardening

corresponding author: S.J. Zinkle, tel. 423-576-7220, fax 423-574-0641, email zinklesj@ornl.gov

MASTER

DISTRIBUTION OF THS DOCUMENT IS
"The submitted manuscript has been authored by a contractor of the U.S. government under contract NO. DE-ACO5960R22464. Accordingly, the U.S. Government retains a nonexclusive, royalty-free license to publish or reproduce the published form of this contribution, or allow others to do so, for U.S. Govemment purposes." 


\section{Introduction.}

One of the most critical issues for the development of an engineering data base for fusion reactor materials is whether data obtained in fission reactors can be used to assess the lifetime of fusion reactor materials. The problem is that currently there are no sufficiently intense $14 \mathrm{MeV}$ neutron sources which would allow samples to be irradiated to doses above 0.1 displacements per atom (dpa), which is the lowest dose that all the most marked radiation damage effects (swelling, helium embrittlement, etc.) start to become significant. One of the key material properties for high heat flux components is the thermal conductivity. A drop in thermal conductivity under irradiation would immediately result in an increase in temperature of high heat flux components. This property is conveniently related to the more-easily measured electrical resistivity by the well-known Wiedemann-Franz law [1].

It is obvious that the available fission reactors cannot simulate all the aspects of the radiation environment which are present in fusion reactors. One disadvantage associated with most mixed spectrum fission reactors is that the high thermal neutron flux produces high concentrations of $\mathrm{Ni}$ and $\mathrm{Zn}$ transmutation products in copper. These solutes are known to strongly reduce the thermal conductivity of copper [1,2]. At present, the effect of transmutant accumulation on mechanical properties is not clearly understood. Recent studies [3,4] suggest that a change in the transmutant accumulation rate may affect changes in the yield strength and uniform elongation in irradiated copper alloys. For example, the threshold softening temperature for precipitation hardened copper alloys was found to be different for specimens irradiated in a mixed spectrum (SM-2) and a fast fission (BOR-60) reactor [3].

In order to more carefully investigate the effect of variations in the transmutant accumulation rate, we have performed a spectrally tailored irradiation experiment on copper and copper alloys. Cadmium shielding was used to reduce the high $\mathrm{Ni}$ and $\mathrm{Zn}$ solid transmutation rate that normally occurs in copper irradiated in mixed-spectrum reactors.

\section{Experimental procedure.}

Sheet tensile samples from pure copper ( $\mathrm{Cu}$ 99.999\%) and the oxide dispersionstrengthened (DS) copper alloys GlidCop A125, GlidCop Al15 and MAGT 0.2 were irradiated in the Channel 4 and Core positions of the SM-2 light water reactor. Specimens were irradiated in aswrought, vacuum annealed, and cold-worked conditions in order to investigate effects of thermomechanical processing. Two different sheet tensile specimen geometries were used [4,5]: The LTS specimen geometry consisted of a gage length of $30 \mathrm{~mm}$ and a thickness of $1 \mathrm{~mm}$. The STS specimen geometry consisted of a gage length of $11 \mathrm{~mm}$ and a thickness of $0.25 \mathrm{~mm}$. Approximately half of the specimens irradiated in the Channel 4 position were enclosed inside a 
$1.5 \mathrm{~mm} \mathrm{Cd}$ shroud in order to reduce the thermal neutron flux. The irradiation produced doses of 0.5 to $1.6 \mathrm{dpa}$ in the Channel 4 position, and 3.5 to $5 \mathrm{dpa}$ in the Core position. Table 1 summarizes the irradiation conditions for these specimens.

The electrical resistivity of all samples was measured at $20 \pm 2^{\circ} \mathrm{C}$ before and after irradiation using standard 4-point probe techniques. The experimental uncertainty in the resistivity measurements was $\pm 0.3 \mathrm{n} \Omega$-m. Tensile testing of the irradiated specimens was subsequently performed in vacuum at $T_{\text {test }} \approx T_{\text {irr }}$. The irradiation and testing techniques are described in more detail in Ref. [4,5].

\section{Results.}

\subsection{Effect of neutron irradiation on electrical resistivity of pure copper and copper alloys.}

\subsubsection{Effect of thermal neutron flux.}

All irradiation capsules contained a complete set of flux monitors for fast and thermal neutrons. These flux measurements and associated calculations made it possible to construct the dependence of electric resistivity increase in irradiated samples on the thermal and fast neutron fluence. As shown in Fig. 1a, the measured electrical resistivity increase was approximately proportional to the thermal neutron fluence for the doses investigated in this study ( 0.5 to $5 \mathrm{dpa})$. Since calculations [6] indicate that $\mathrm{Ni}$ and $\mathrm{Zn}$ are the dominant transmutation products in irradiated copper for the SM-2 Core and Channel 4 spectra, the solid transmutation contribution to the electric resistivity increase can be estimated by the following formula, where $\mathrm{K}_{\mathrm{Ni}}=11.2 \mathrm{n} \Omega-\mathrm{m} / \mathrm{at} . \%$ and $\mathrm{K}_{\mathrm{Zn}}=3.0 \mathrm{n} \Omega-\mathrm{m} / \mathrm{at} \%[1]$ :

$$
\Delta \rho_{\mathrm{tr}}=\Delta \rho_{\mathrm{Ni}}+\Delta \rho_{\mathrm{Zn}}=K_{\mathrm{Ni}} \mathrm{C}_{\mathrm{Ni}}+\mathrm{K}_{\mathrm{Zn}} \mathrm{C}_{\mathrm{Zn}}
$$

The $\mathrm{Ni}$ and $\mathrm{Zn}$ production is predominantly due to thermal neutron $(\mathrm{n}, \gamma)$ reactions with ${ }^{63} \mathrm{Cu}$ and ${ }^{65} \mathrm{Cu}$, which produce the unstable isotopes ${ }^{64} \mathrm{Cu}$ and ${ }^{66} \mathrm{Cu}$, respectively. The ${ }^{66} \mathrm{Cu}$ isotope rapidly decays by emitting a beta particle to produce the stable ${ }^{66} \mathrm{Zn}$ isotope. The ${ }^{64} \mathrm{Cu}$ isotope rapidly decays by emitting either a beta particle or a positron to produce the stable ${ }^{64} \mathrm{Zn}$ or ${ }^{64} \mathrm{Ni}$ isotopes, respectively. The production of $\mathrm{Ni}$ and $\mathrm{Zn}$ from the ${ }^{63} \mathrm{Cu}(\mathrm{n}, \gamma)$ reaction is given by

$$
\begin{aligned}
& \mathrm{C}_{\mathrm{Ni}}=0.63 \sigma_{\mathrm{Cu}}{ }^{63} \bullet \mathrm{C}_{\mathrm{Cu}} \bullet \Phi \mathrm{t}_{\mathrm{th}} \\
& \mathrm{C}_{\mathrm{Zu}_{\mathrm{a}}}=0.37 \sigma_{\mathrm{Cu}}{ }^{63} \bullet \mathrm{C}_{\mathrm{Cu}} \bullet \Phi \mathrm{t}_{\mathrm{th}}
\end{aligned}
$$


where the factors of 0.63 and 0.37 represent the relative partitioning between beta and positron decay of ${ }^{64} \mathrm{Cu}, \Phi \mathrm{t}_{\mathrm{th}}$ is the thermal fluence, and $\sigma_{\mathrm{Cu}}{ }^{63}$ is the spectrum-averaged cross-section for production of ${ }^{63} \mathrm{Cu}\left(\sigma_{\mathrm{Cu}}{ }^{63} \sim 4.5 \times 10^{-28} \mathrm{~m}^{2}\right.$ in the unshielded Channel 4 position).

When comparing the calculated trend line of the transmutation contribution $\left(\Delta \rho_{t r}\right)$ and the trend line connecting the experimental points $\Delta \rho_{\text {tot }}=\Delta \rho_{\text {rd }}+\Delta \rho_{\text {tr }}$, it can be seen that they are nearly parallel with perhaps a slight increase in $\Delta \rho_{\text {tot }}$ at the highest thermal fluence (Fig. 1). This indicates that the radiation defect component of the resistivity increase $\left(\Delta \rho_{\mathrm{rd}}\right)$ has achieved a saturation level and is essentially independent of the thermal neutron fluence. This behavior is expected, as $\Delta \rho_{\mathrm{rd}}$ should depend primarily on the level of displacement damage (dpa), and thermal neutrons have a negligible contribution to the displacement damage in the SM-2 reactor. Furthermore, the specimens in the present study received doses of 0.5 to $5 \mathrm{dpa}$, which is above the dose of $\sim 0.1 \mathrm{dpa}$ needed to achieve a saturation defect cluster density in copper irradiated at temperatures below $150^{\circ} \mathrm{C}$ [7]. The resistivity data for pure $\mathrm{Cu}$ in Fig. la can be described by the following phenomenological equation, where $\mathrm{K}=3.5 \mathrm{n} \Omega-\mathrm{m}$ per $10^{25} \mathrm{n} / \mathrm{m}^{2}$ :

$$
\Delta \rho_{\mathrm{tot}}=\Delta \rho_{\mathrm{rd}}+\Delta \rho_{\mathrm{tr}}=1.2 \mathrm{n} \Omega-\mathrm{m}+\mathrm{K} \bullet \Phi \mathrm{t}_{\mathrm{th}}
$$

This experimentally measured value of $\mathrm{K}$ is about $20 \%$ higher than the calculated value ( $2.88 \mathrm{n} \Omega$ m per $10^{25} \mathrm{n} / \mathrm{m}^{2}$ ) obtained from equations (1-3), which may be due to a combination of experimental error and uncertainties in the spectrum-averaged value of the transmutation crosssection for $\mathrm{Cu}$ in the $\mathrm{SM} 2$ reactor channels.

The data in Fig. 1a suggest that there may be a slight nonlinearity at thermal neutron fluences above $1 \times 10^{25} \mathrm{n} / \mathrm{m}^{2}$, although higher fluence data are needed to confirm this possibility. As discussed later (section 4.1), it is possible that the transmutant solute concentration generated at high thermal neutron fluences may stabilize solute-defect cluster complexes. Alternatively, it is possible that nonlinear effects such as the production of $\mathrm{Ga}$ and $\mathrm{Ge}$ via multistep reactions may be occurring at these high fluences. Further analysis is required to investigate this possibility (200 to 400 appm of $\mathrm{Ga}$ or Ge would produce an additional resistivity increase of $\sim 0.6 \mathrm{n} \Omega-\mathrm{m}$ ), and also to rule out possible errors in the calculated $\mathrm{Ni}, \mathrm{Zn}$ concentration.

For the DS alloys, the $\Delta \rho_{\text {tot }}$ dependence on $\Phi t_{\text {th }}$ (Fig. 1b) is qualitatively the same as for pure copper. However, the quantitative value of $\Delta p_{\text {tor }}$ for thermal neutron fluences up to $1 \times 10^{25}$ $\mathrm{n} / \mathrm{m}^{2}$ is generally higher for the DS alloys, and as $\Delta \rho_{\mathrm{t}}$ for pure copper and DS alloys should be practically the same (since the solid transmutations are predominantly produced by reactions with the $\mathrm{Cu}$ matrix), this suggests that some mechanism may be enhancing the $\Delta \rho_{\mathrm{rd}}$ component in DS alloys. The estimated value of $\Delta \rho_{\mathrm{rd}}$ from the data in Fig. $1 \mathrm{~b}$ is $1.6 \mathrm{n} \Omega-\mathrm{m}$. Possible mechanisms for the larger $\Delta \rho_{\mathrm{rd}}$ for the DS alloys are enhanced stabilization of Frenkel pair defects or partial radiation-induced dissolution of the $\mathrm{Al}_{2} \mathrm{O}_{3}$ particles. Ballistic dissolution of the particles would 
increase the alloy resistivity, due to the high specific resistivity of Al solute in copper. Finally, it is worth noting that the electrical resistivity was higher for boron-doped DS copper alloys (unfilled data points in Fig. 1b) irradiated to thermal neutron fluences above $5 \times 10^{24} \mathrm{n} / \mathrm{m}^{2}$, most likely due to the additional resistivity increase associated with transmutation of ${ }^{10} \mathrm{~B}$. According to the data in ref. [8], a resistivity increase of $\sim 0.5 \mathrm{n} \Omega-\mathrm{m}$ would be expected from the $\mathrm{He}$ and $\mathrm{Li}$ produced by the transmutation of the $\sim 100 \mathrm{ppm}$ boron in these alloys.

\subsubsection{Effect of irradiation temperature.}

Irradiation of samples in the Core position at 100 to $400^{\circ} \mathrm{C}$ allowed for an assessment of irradiation temperature effects on $\Delta \rho_{\text {tor. }}$. Samples in the three different Core capsules were irradiated to approximately the same level of damage, i.e. $~ 3.5$ to 5 dpa (Table 1). Figs $2 \mathrm{a}$ and $2 \mathrm{~b}$ demonstrate $\Delta \rho_{\text {tot }}$ decreases steadily with increasing irradiation temperature. The difference in $\Delta \rho_{\text {tot }}$ (measured at $20^{\circ} \mathrm{C}$ ) for irradiation temperatures of $100 \mathrm{vs.} 400^{\circ} \mathrm{C}$ was about $2 \mathrm{n} \Omega$-m for pure copper and $\sim 2.5 \mathrm{n} \Omega$-m for the DS alloys.

Since the production of solid transmutants is independent of irradiation temperature, the data in Fig. 2 suggest that the decrease in $\Delta \rho_{\text {tot }}$ is associated with a decrease in $\Delta \rho_{\text {rd }}$ with increasing irradiation temperature (i.e., thermal instability of the radiation defects). It is possible that thermal-

enhanced solute segregation to defect sinks could also contribute to the observed decrease in $\Delta \rho_{\text {tot }}$ at elevated irradiation temperatures, which would explain why the resistivity increase measured at temperatures above $-300^{\circ} \mathrm{C}$ is less than the calculated increase due to solute transmutants. The magnitude of $\Delta \rho_{\text {tot }}$ in copper approaches the level expected from transmutation reactions alone $\left(\Delta \rho_{t r}\right)$ at an irradiation temperature of $\sim 250-300^{\circ} \mathrm{C}$. The resistivity change observed in the DS copper alloys irradiated at $350-400^{\circ} \mathrm{C}$ was $\sim 0.5 \mathrm{n} \Omega-\mathrm{m}$ higher than that observed in pure $\mathrm{Cu}$ (Fig. 2), which might be due to increased resistivity associated with partial radiation-induced dissolution of the $\mathrm{Al}_{2} \mathrm{O}_{3}$ particles.

\subsection{Effect of neutron irradiation on the yield strength of pure copper and copper alloys.}

Both pure copper and the DS copper alloys were significantly hardened by neutron irradiation at low temperature $\left(80\right.$ to $\left.100^{\circ} \mathrm{C}\right)$. In general, no appreciable difference in the yield strength increase $\left(\Delta \sigma_{\mathrm{Y}}\right)$ was observed for doses of 0.5 to $5 \mathrm{dpa}$ at these irradiation temperatures, indicating that the radiation hardening had reached a saturation condition already at a dose of 0.5 dpa. By comparison with previously published studies on copper and copper alloys, it may be concluded that hardening generally approaches saturation at $T_{\text {irr }}<150^{\circ} \mathrm{C}$ for doses above 0.1 dpa $[1,7,9,12]$. The one exception to this dose-independent behavior was cold-worked copper, which 
reached a maximum strength of $\sim 450 \mathrm{MPa}$ at a dose of $\sim 1$ dpa and then decreased to $\sim 300 \mathrm{MPa}$ at $4.5 \mathrm{dpa}$. The irradiated yield strengths $\left(\sigma_{\text {Yir }}\right)$ for annealed pure copper, cold-worked pure copper and the DS copper alloys were different and varied in a rather wide range (from $-200-250 \mathrm{MPa}$ for annealed copper to 500-550 MPa for GlidCop AL25 and MAGT 0.2). On the other hand, the value of the $\sigma_{\text {Yir }}$ increase was approximately the same for all materials and amounted to $\sim 150$ to $200 \mathrm{MPa}$. The low-temperature radiation hardening data are summarized in a companion paper in these proceedings [9].

Figs. 3 and 4 demonstrate that the yield strength decreases with increasing irradiation temperature for all of the materials. The most significant amount of radiation hardening occurs at irradiation temperatures below $\sim 200^{\circ} \mathrm{C}$. It is worth noting that the yield strength of cold-worked copper is significantly higher than annealed copper at low irradiation temperatures, but their yield strengths are similar for irradiation temperatures above $150^{\circ} \mathrm{C}$. A small amount of radiation hardening ( $50-100 \mathrm{MPa})$ was observed in annealed and cold-worked pure copper specimens at irradiation temperatures between 200 and $400^{\circ} \mathrm{C}$. On the other hand, the yield strength of the irradiated DS copper alloys becomes comparable to the unirradiated values for $\mathrm{T}_{\mathrm{ir}} \geq 200^{\circ} \mathrm{C}$.

The large amount of radiation hardening observed at $\mathrm{T}_{\mathrm{irm}}<200^{\circ} \mathrm{C}$ is known to be due to small defect clusters (stacking fault tetrahedra and dislocation loops) [10-12]. These defect clusters are thermally unstable in copper at irradiation temperatures above $\sim 150^{\circ} \mathrm{C}[7,11,13]$, which explains the approach of the irradiated yield strengths to the unirradiated values. The slight residual radiation hardening in pure copper at $\mathrm{T}_{i r} \sim 200$ to $400^{\circ} \mathrm{C}$ may be caused by the emergence of another type of defect. This effect can be interpreted in detail only after TEM investigations, but we can speculate that the strengthening might be associated with void formation in pure copper in this temperature range $[11,14]$.

\section{Discussion.}

Chaplin and Coltman [15] measured the dose-dependent electrical resistivity changes in copper due to radiation defects and transmutations, and concluded that the saturation value of $\Delta \rho_{\text {rd }}$ for copper irradiated with fission neutrons near $50^{\circ} \mathrm{C}$ was about $0.8 \mathrm{n} \Omega-\mathrm{m}$ at a measurement temperature of $\sim 20^{\circ} \mathrm{C}$. This value is significantly less than the values determined in the present study of $\Delta \rho_{\mathrm{rd}} \sim 1.2 \mathrm{n} \Omega-\mathrm{m}$ for copper and $\Delta \rho_{\mathrm{rd}} \sim 1.6 \mathrm{n} \Omega-\mathrm{m}$ for the DS copper alloys. It should be noted that the saturation value of $\Delta \rho_{\mathrm{rd}}$ in the previous study [15] was obtained by extrapolation of low-dose data $(<0.04 \mathrm{dpa}$ ) which were below the minimum dose necessary to achieve a saturation defect cluster density $(\sim 0.1 \mathrm{dpa})$, and was about two orders of magnitude smaller than the maximum dose achieved in the present study. 
The present results permit us to analyze the effect of dose, irradiation temperature and neutron spectrum on the increase in electric resistivity and yield strength of pure copper alloys. As noted above, the $\Delta p_{t r}$ characteristics depend weakly on the damage dose and irradiation temperature, since they are due to nuclear reactions. On the other hand, the solid solution hardening associated with $\mathrm{Ni}$ and $\mathrm{Zn}$ concentrations of $\sim 0.1$ to $1 \%$ should increase the yield strength of copper by only 10 to $20 \mathrm{MPa}$ per $1 \%$ solute [1]. Thus, the most interesting subject matter to analyze is the comparative investigation of the characteristics of $\Delta \sigma_{Y}$ and $\Delta \rho_{\mathrm{rd}}$, where $\Delta \sigma_{Y}=\sigma_{\text {Yirr }}-\sigma_{\text {Yunir }}$ and $\Delta \rho_{\mathrm{rd}}=\Delta \rho_{\text {tot }}-\Delta \rho_{\mathrm{tr}}$. The value of $\Delta \rho_{\mathrm{tr}}$ can be calculated for each specimen from the measured thermal neutron fluence using equations (1)-(3). This allows $\Delta \rho_{\mathrm{rd}}$ to be calculated from the experimental data and enables a comparison to be made of the effect of $T_{\text {irr }}$ and dpa on the behavior of $\Delta \rho_{\mathrm{rd}}$ and $\Delta \sigma_{\mathrm{Y}}$. Both properties depend primarily on the radiation defect density and should be, in principal, comparably affected by changes in irradiation conditions.

Figs. 2-4 reveal the similar dependence of $\Delta \rho_{\mathrm{rd}}$ and $\Delta \sigma_{\mathrm{Y}}$ on the irradiation temperature for

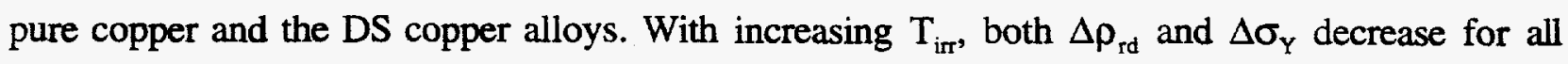
materials and approach zero for $\mathrm{T}_{\mathrm{irr}} \sim 200$ to $300^{\circ} \mathrm{C}$. As shown in Ref. [13], the defect cluster density in copper irradiated at a damage rate of $\sim 10^{-7} \mathrm{dpa} / \mathrm{s}$ begins to decrease rapidly for irradiation temperatures above $-150^{\circ} \mathrm{C}$ due to the thermal instability of the predominantly vacancy-type defect clusters (recovery Stage V). The defect cluster density at an irradiation temperature of $300^{\circ} \mathrm{C}$ is only $\sim 1 \times 10^{22} / \mathrm{m}^{3}$ [13], which produces negligible (<35 $\left.\mathrm{MPa}\right)$ radiation hardening. The corresponding resistivity increase associated with this defect cluster density is also negligible $(\sim 0.01 \mathrm{n} \Omega-\mathrm{m})$, according to the analysis given in ref. [16].

\subsection{Effect of neutron spectrum on $\Delta \rho_{r d}$ and $\Delta \sigma_{Y}$}

Fig. 5 shows $\Delta \rho_{\text {rd }}$ for a number of Cu-based materials irradiated with and without $\mathrm{Cd}$ shielding at $T_{\text {irr }} \sim 80$ to $90^{\circ} \mathrm{C}$. It is evident that, despite a large spread in the data points, the electrical resistivity increase caused by radiation defects in the $\mathrm{Cd}$-shielded specimens is systematically lower than in unshielded specimens. The difference in the Cd-shielded vs. unshielded curves is considerable, $\sim 1 \mathrm{n} \Omega-\mathrm{m}$. This observation indicates that thermal neutrons have a significant effect on either the damage formation or on the formation of solute-defect complexes. The calculated $\mathrm{Ni}$ and $\mathrm{Zn}$ concentration in copper samples irradiated without $\mathrm{Cd}$ shielding is about seven times higher than that for samples irradiated in $\mathrm{Cd}$-shielded positions to the same damage level. This may stimulate the segregation of $\mathrm{Ni}$ and $\mathrm{Zn}$ on the complexes of defects (defect clusters and dislocations). It has been observed in a previous TEM study that the formation of dislocation loops was strongly enhanced in copper alloys such as $\mathrm{Cu}-5 \% \mathrm{Ni}$ following irradiation with 750 $\mathrm{MeV}$ protons to $\sim 1 \mathrm{dpa}$ at $\mathrm{T}_{\mathrm{irr}} \sim 100$ to $150^{\circ} \mathrm{C}[13]$. 
Since the Core position and the Cd-shielded Channel 4 position have a comparable fast- to thermal-flux ratio of $\Phi_{\text {fasl }} / \Phi_{\text {th }} \sim 4$ to 7 , it is interesting to construct the dose dependence of the $\Delta \rho_{\text {rd }}$ increase for pure copper samples irradiated in both positions. As indicated in Fig. 6, the value of $\Delta \rho_{\mathrm{rd}}$ is constant over the dose range of 0.5 to 5 dpa that corresponds to these two positions.

Whereas the derived value of $\Delta \rho_{\mathrm{rd}}$ was systematically higher for all specimens irradiated in a high thermal neutron flux, the corresponding values of $\Delta \sigma_{\text {Yir }}$ generally did not show a similar strong dependence on neutron spectrum. The yield strength of annealed copper irradiated at $\sim 100^{\circ} \mathrm{C}$ in an unshielded Channel 4 position was typically $\sim 50 \mathrm{MPa}$ higher than annealed copper specimens irradiated in a Cd-shielded position [9]. However, the yield strength of cold-worked copper and DS copper alloys was similar in Cd-shielded and unshielded positions. This difference in behavior can be understood by consideration of the superposition laws for yield strength increase [17]. If it is assumed that the enhanced resistivity associated with a high thermal neutron flux is due to small solute-defect cluster complexes, then the strengthening contribution from these relatively weak barriers could be masked by the presence of a high concentration of strong dislocation barriers such as oxide particles or network dislocations. Therefore, the neutron spectrum effect on the yield strength would be strongest in annealed copper specimens and would be nearly undetectable in the DS copper alloys.

The present electrical resistivity and tensile results indicate that the $\mathrm{Ni}$ and $\mathrm{Zn}$ transmutation products have a measurable effect on the physical and mechanical properties of irradiated copper alloys. This suggests that these solutes may also affect the microstructural development of irradiated copper alloys. Therefore, the irradiation spectrum in copper irradiation experiments should be tailored (if necessary) so that the solid transmutation rate is comparable to that anticipated in fusion energy systems. As shown in Fig. 7, the production of $\mathrm{Ni}$ and $\mathrm{Zn}$ transmutants (per dpa) in the Core and Cd-shielded Channel 4 positions of the SM-2 reactor shows fair agreement with the expected ITER value. On the other hand, the solid transmutation rate in the unshielded Channel 4 position is an order of magnitude higher than the ITER value. An additional advantage of the Core position is that it allows high damage levels to be examined due to its high damage rate of $\sim 10$ $\mathrm{dpa} / 100$ days ( $0.1 \mathrm{dpa} /$ day $)$.

\section{Conclusions.}

The study of changes in electrical resistivity and yield strength of samples from pure copper and DS copper alloys revealed that there is a well-defined correlation in the behavior of the components $\Delta \rho_{\text {tot }}=\Delta \rho_{\mathrm{rd}}+\Delta \rho_{\mathrm{tr}}$ and the fast and thermal parts of the neutron spectrum. The $\Delta \rho_{\mathrm{tr}}$ component depends primarily on the thermal neutron flux. It is determined by the transmutation rate (mainly $\mathrm{Ni}$ and $\mathrm{Zn}$ solutes) and has a weak dependence on the fast neutron flux and irradiation 
temperature. The second component, $\Delta \rho_{\mathrm{rd}}$, is determined mainly by the level of radiation damage, and reduces practically to zero as the irradiation temperature approaches $250^{\circ} \mathrm{C}$. The increase in $\Delta \rho_{\text {rd }}$ correlates with the increase in yield strength, $\Delta \sigma_{\text {Yir }}$, since both of these properties are determined by the density of defect complexes. The comparison of the dose dependence of $\Delta \rho_{\mathrm{rd}}$ for samples irradiated with and without $\mathrm{Cd}$ shielding in Channel 4 indicates that irradiation with thermal neutrons results in an increase in $\Delta \rho_{\mathrm{rd}}$ (i.e., defect density), probably because of some effect of $\mathrm{Ni}$ and $\mathrm{Zn}$ on dislocation loop formation and the development of defect complexes. The magnitude of $\Delta \rho_{\text {rd }}$ appears to be $\sim 30 \%$ higher in the DS copper alloys compared to pure copper, most likely because of partial dissolution of the oxide particies.

The tensile and electrical properties of copper alloys are influenced by the solid transmutation generation rate. Therefore, fusion engineering data on irradiated copper alloys should preferably be obtained in facilities where the solid transmutation rate is comparable to the fusion condition. The Core position of the SM-2 reactor produces fusion-relevant solid transmutation rates in copper. but most other mixed spectrum reactors may require spectral tailoring to reduce the $\mathrm{Ni}$ and $\mathrm{Zn}$ transmutation rates to fusion-relevant levels.

\section{Acknowledgements}

Research sponsored in part by the Office of Fusion Energy, U.S. Department of Energy under contracts DE-AC05-96OR22464 with Lockheed Martin Energy Research Corp. and DE-AC0676RLO 1830 with Battelle Memorial Institute, and in part by the European Fusion Technology Programme.

\section{References}

[1] S.J Zinikle and S.A. Fabritsiev, Atomic and Plasma Materials Interaction Data for Fusion (supplement to Nuclear Fusion) 5 (1994) 163-192.

[2] H.M. Frost and J.C. Kennedy, J. Nucl. Mater. 141-143 (1986) 169-173.

[3] S.A. Fabritsiev, A.S. Pokrovsky, V.R. Barabash, Yu.G. Prokofiev, Neutron spectrum and transmutation effect on properties of copper alloys, Fusion Eng. and Design, in press.

[4] A.S. Pokrovsky, A.A. Melder, and S.A. Fabritsiev, Methodology of spectral tailoring experiment in SM-2 reactor. presented at ICFRM-7 (these proceedings). 
[5] S.A. Fabritsiev, A.S. Pokrovsky, S.J. Zinkle, A.F. Rowcliffe, B.N. Singh, F.A. Garner and D.J. Edwards, in Fusion Reactor Materials semiann. prog. report for period ending Sept. 30 , 1994, DOE/ER-0313/17, pp. 221-228.

[6] A.V. Karasiov and S.A. Fabritsiev, The Effect of Neutron Spectrum on Transmutant Accumulation in ITER Structural Materials, presented at ICFRM-7 (these proceedings).

[7] B.N. Singh and S.J. Zinkle, J. Nucl. Mater. 206 (1993) 212-229.

[8] P. Vela and B. Russell, J. Nucl. Mater. 19 (1966) 312.

[9] S.A. Fabritsiev, A.S. Pokrovsky, S.J. Zinkle, D.J. Edwards, Low-temperature embrittlement of copper alloys, presented at ICFRM-7, Obninsk 1995 (these proceedings).

[10] T.J. Koppenaal and R.J. Arsenault, Metall. Rev. 16 (1971) 175-196.

[11] S.J. Zinkle, in 15th Int. Symp. on Effects of Radiation on Materials, ASTM STP 1125, eds. R.E. Stoller et al. (Amer. Soc. Testing and Mater., Philadelphia, 1992) 813-834.

[12] B.N. Singh, A. Horsewell, P. Toft and D.J. Edwards, J. Nucl. Mater. 224 (1995) 131; also B.N. Singh et al., presented at ICFRM-7, submitted to J. Nucl. Mater.

[13] S.J. Zinkle, A. Horsewell, B.N. Singh and W.F. Sommer, J. Nucl. Mater. 212-215 (1994) 132-138.

[14] R.O. Scattergood and D.J. Bacon, Acta Met. 30 (1982) 1665-1677.

[15] R.L. Chaplin and R.R. Coltman, Jr., J. Nucl. Mater. 108\&109 (1982) 175.

[16] S.J. Zinkle, J. Phys. F: Metal Physics 18 (1988) 377-391.

[17] G.E. Lucas, J. Nucl. Mater. 206 (1993) 287-305. 
Table 1. Summary of maximum irradiation fluences and average irradiation temperatures for the 5 different capsules.

\begin{tabular}{|c|c|c|c|c|}
\hline \multirow{2}{*}{ Position } & \multicolumn{2}{|c|}{ Fluence, $10^{25} \mathrm{n} / \mathrm{m}^{2}$} & Dose (dpa) & $T_{\text {ir }}\left({ }^{\circ} \mathrm{C}\right)$ \\
\cline { 2 - 5 } & Fast, E>0.1 MeV & Thermal, E<0.68eV & \\
\hline $\begin{array}{c}\text { Channel 4 } \\
\text { without Cd }\end{array}$ & 2.27 & 1.4 & 1.6 & 88 \\
\hline $\begin{array}{c}\text { Channel 4 } \\
\text { with Cd }\end{array}$ & 1.78 & 0.292 & 1.3 & 88 \\
\hline Core 1 & 6.5 & 0.91 & 4.5 & 100 \\
\hline Core 3 & 7.8 & 0.87 & 5.5 & 260 \\
\hline Core 4 & 7.7 & 0.86 & 5.4 & 360 \\
\hline
\end{tabular}




\section{List of Figure captions}

Fig. 1. Measured change in electrical resistivity vs. thermal neutron fluence for a) pure copper and b) DS copper alloys. The open data points in Fig. $1 \mathrm{~b}$ were obtained from boron-doped specimens which apparently produced a higher amount of resistivity (see text).

Fig. 2. Effect of irradiation temperature on the electrical resistivity change of a) pure copper and b) DS copper alloys irradiated in the Core position of the SM-2 reactor.

Fig. 3. Effect of irradiation temperature on the yield strength of pure copper. The filled symbols refer to cold-worked copper and the open symbols denote annealed copper specimens. The solid lines indicate the temperature-dependent yield strengths of annealed (lower curve) and cold-worked (upper curve) copper prior to irradiation.

Fig. 4. Effect of irradiation temperature on the yield strength of DS copper alloys. The solid line indicates the temperature-dependent yield strength of DS copper.

Fig. 5. Comparison of the radiation defect part of the electrical resistivity change for specimens irradiated in Cd-shielded and unshielded regions of Channel 4 capsules.

Fig. 6. Dose dependence of the radiation defect part of the electrical resistivity change for specimens irradiated in Cd-shielded Channel 4 and Core capsules.

Fig. 7. Comparison of the dose-dependent electrical resistivity changes calculated for the ITER first wall neutron spectrum and various positions in the SM-2 mixed spectrum reactor. 
Fabritsreu etal Frg. la

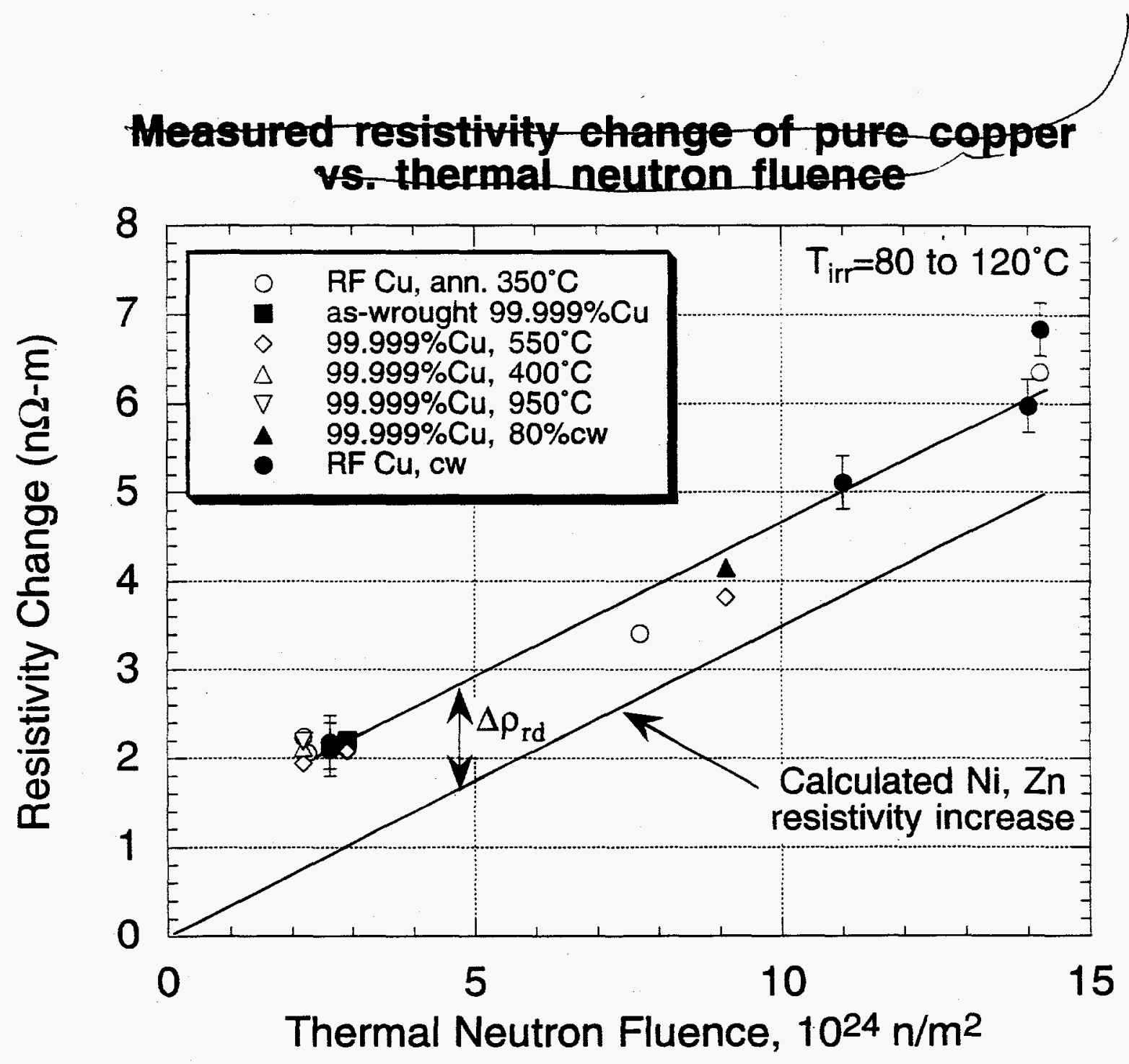




$$
\begin{aligned}
& \text { Fabntsrevetal, } \\
& \text { Fig. } 16
\end{aligned}
$$

Measured resistivity change in DS copper altoys *9. thermal noutron fluence

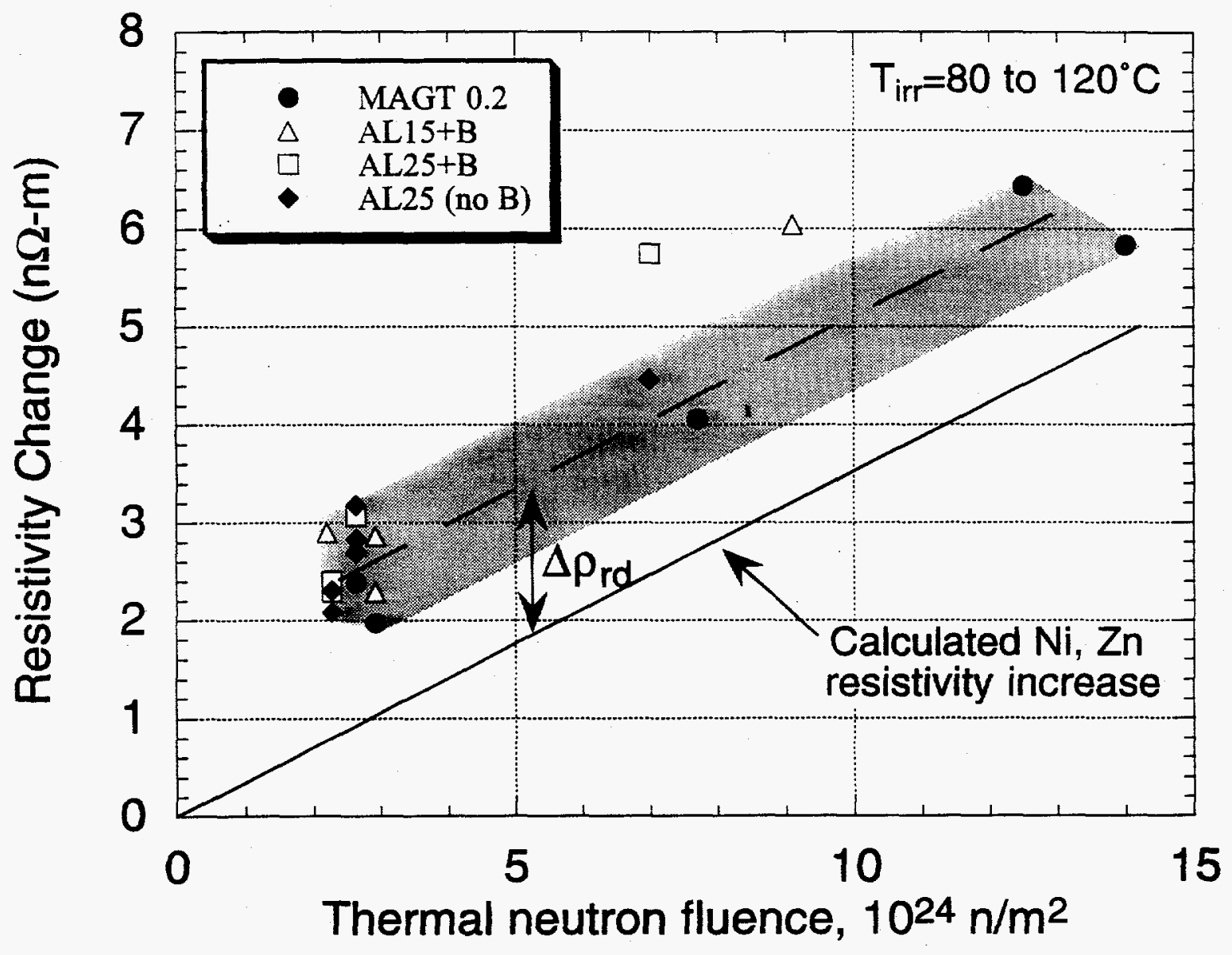




\section{Fabritsiev et al, Fig. $2 a$}

\section{Irradiation Temperature Effect on the Electrical Resistivity of Pure Copper (SM2 core)}

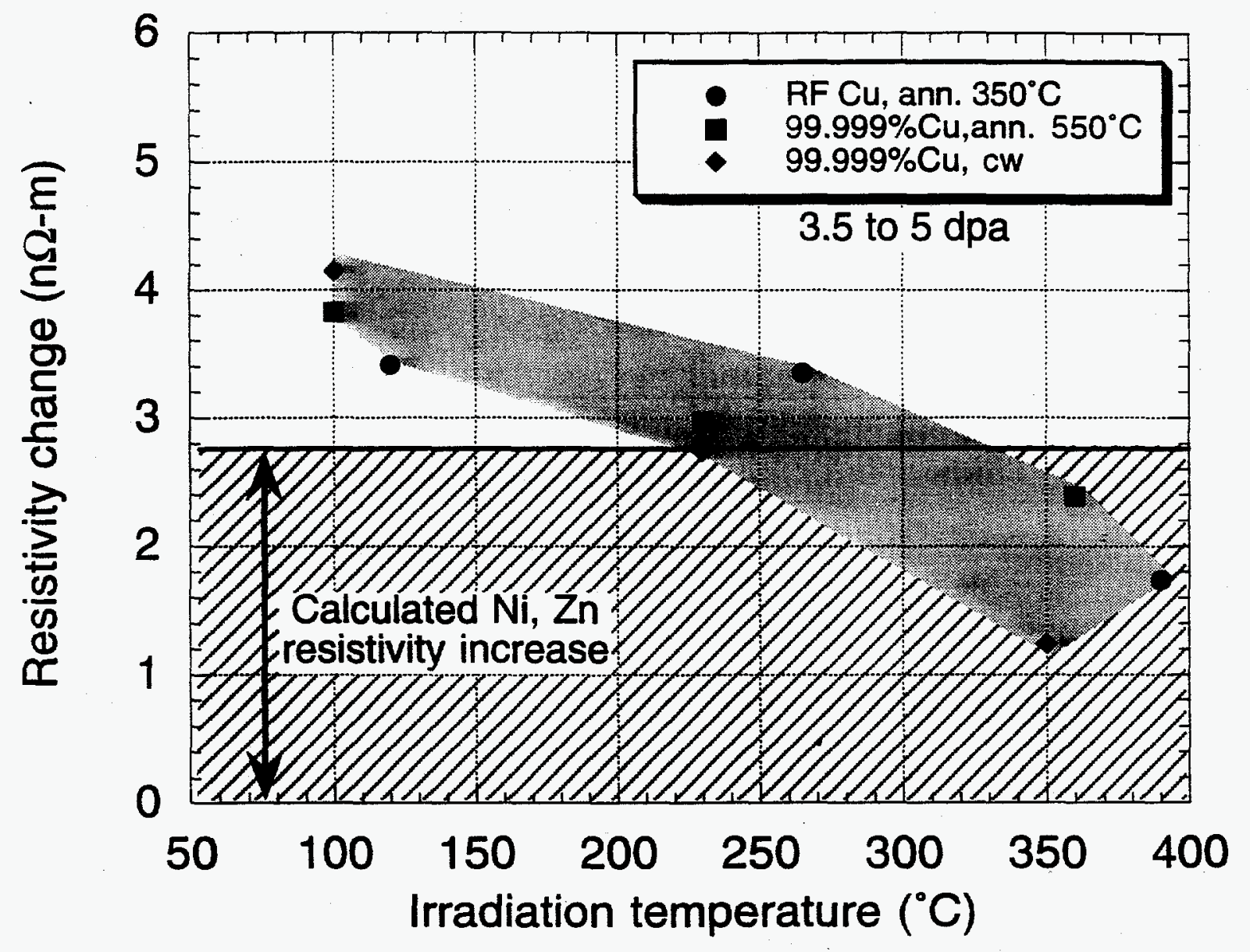


Fabritsiev etal.

Fig. $2 b$

Irradiation Temperature Effect on the
Electrical Resistivity of DS Cu Alloys (SM2 core)

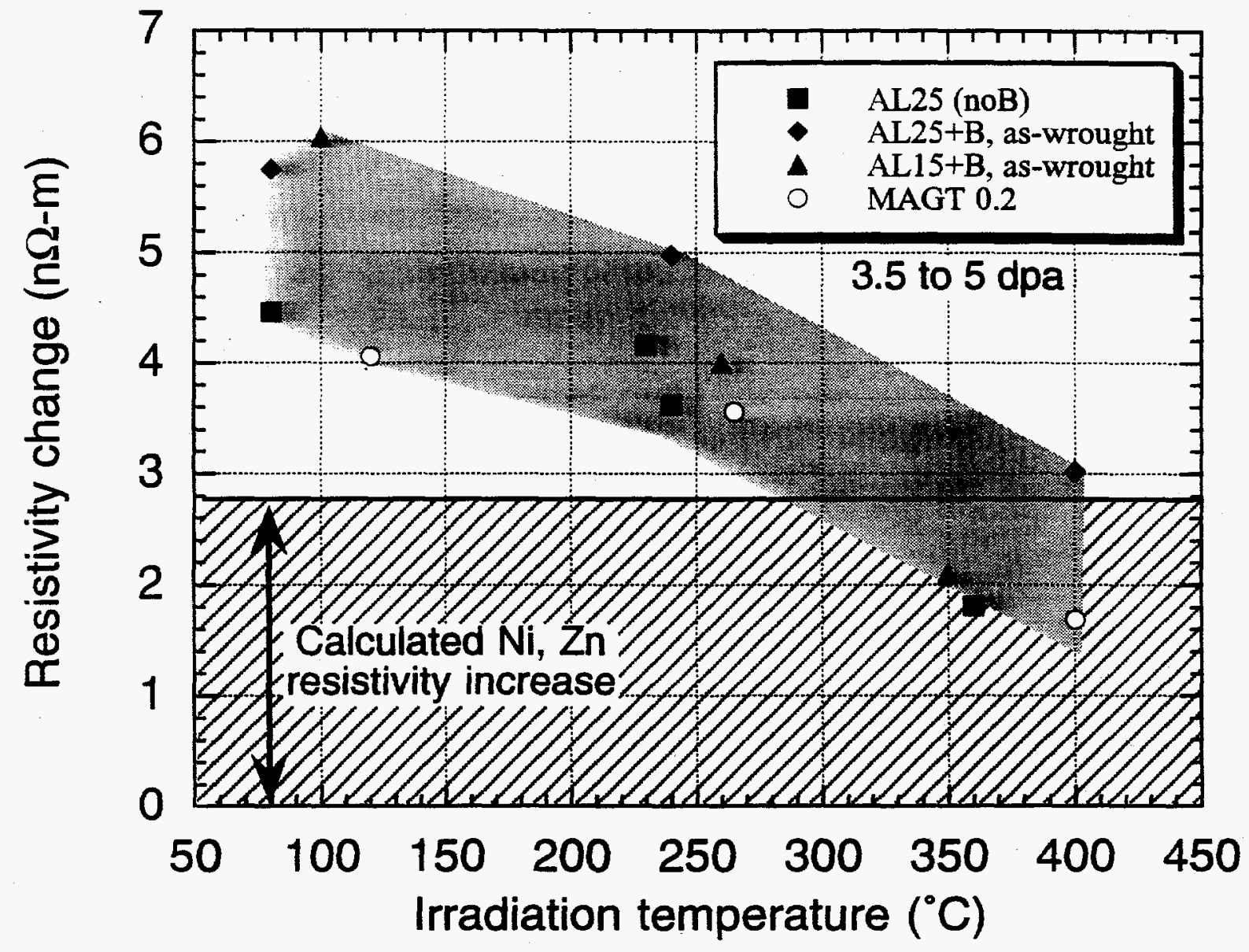




$$
\begin{aligned}
& \text { Fabritsieu atal. } \\
& \text { Frg. } 3
\end{aligned}
$$

\section{Effect of Irradiation Temperature on the Yield Strength of Copper}

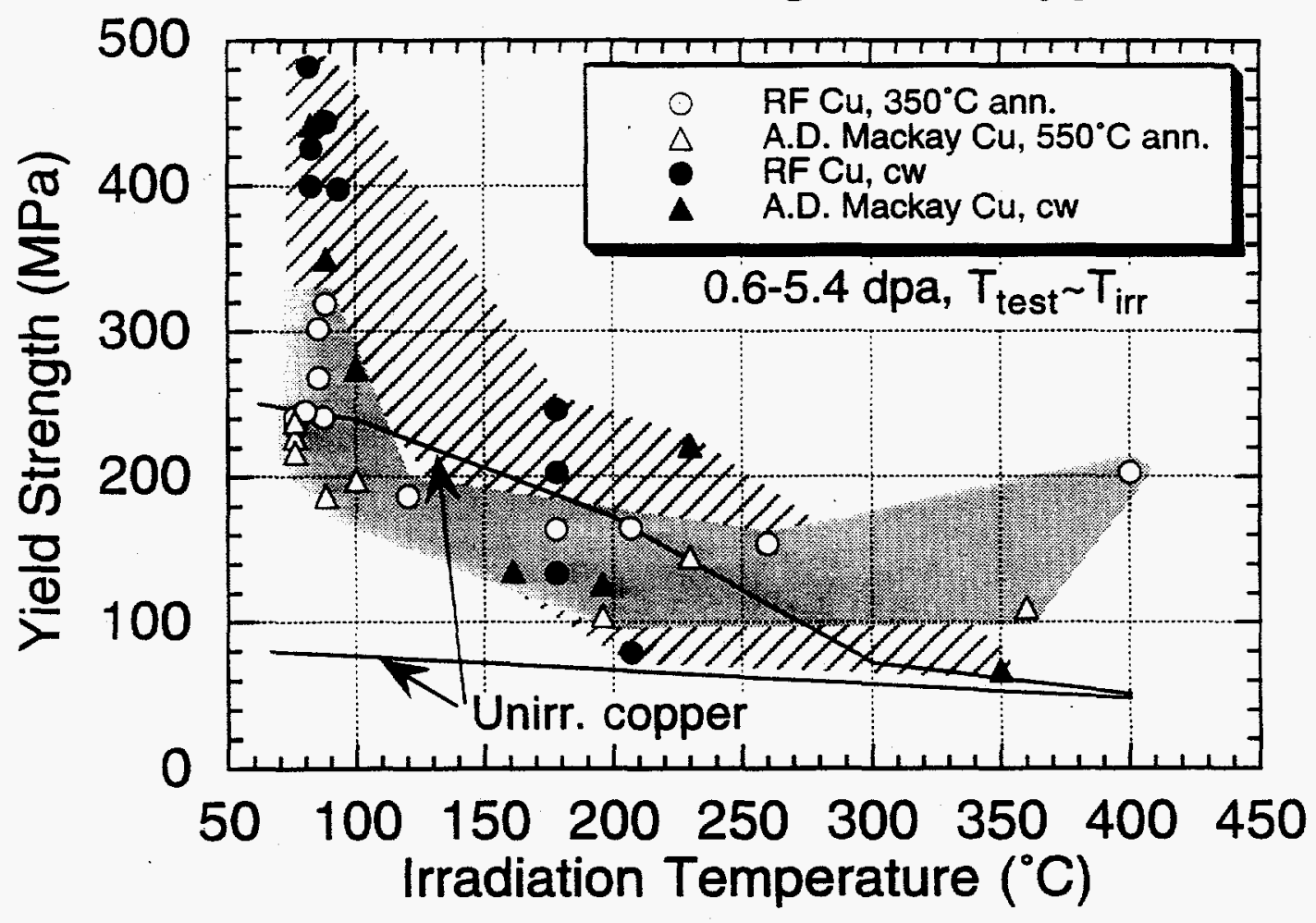




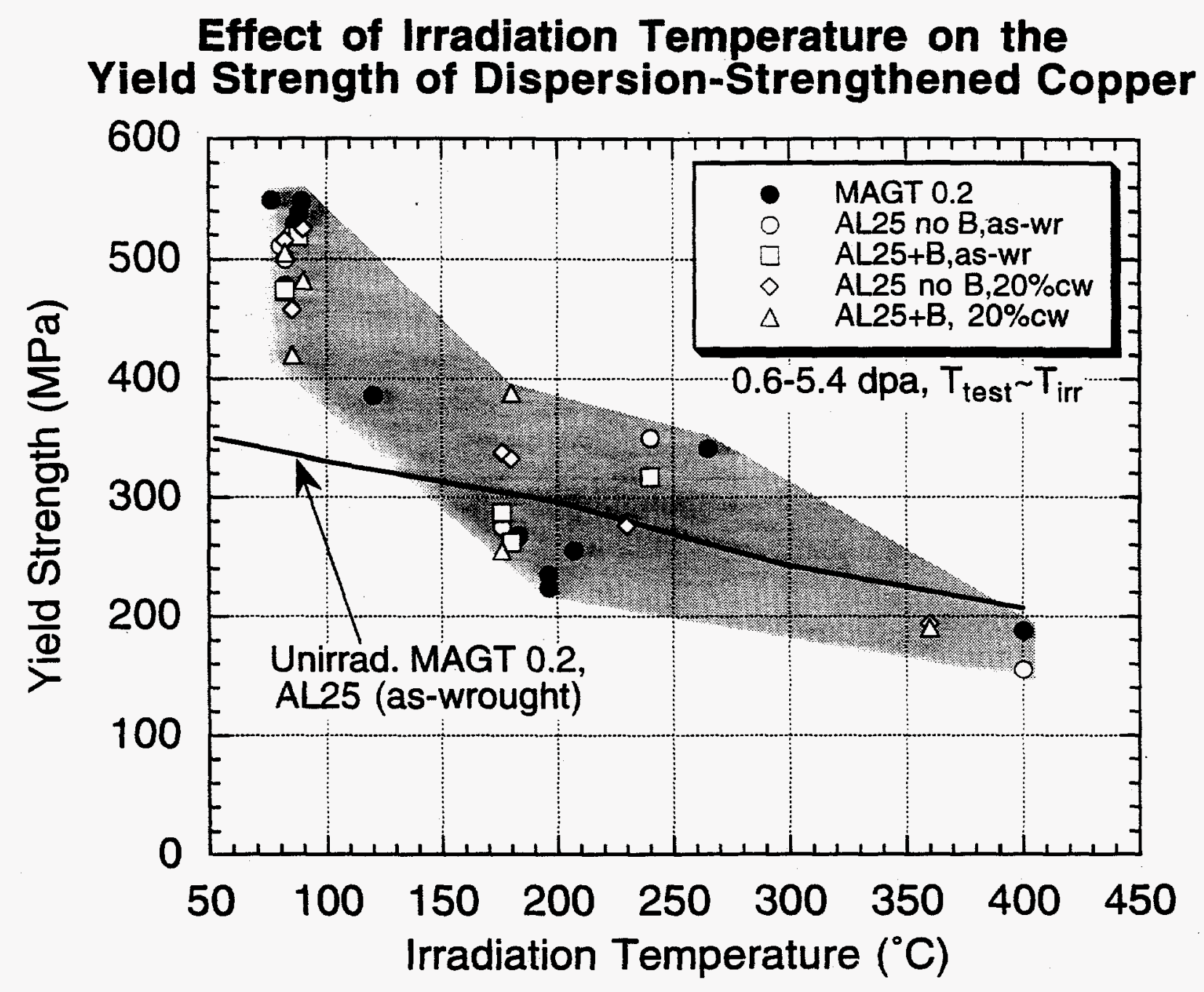




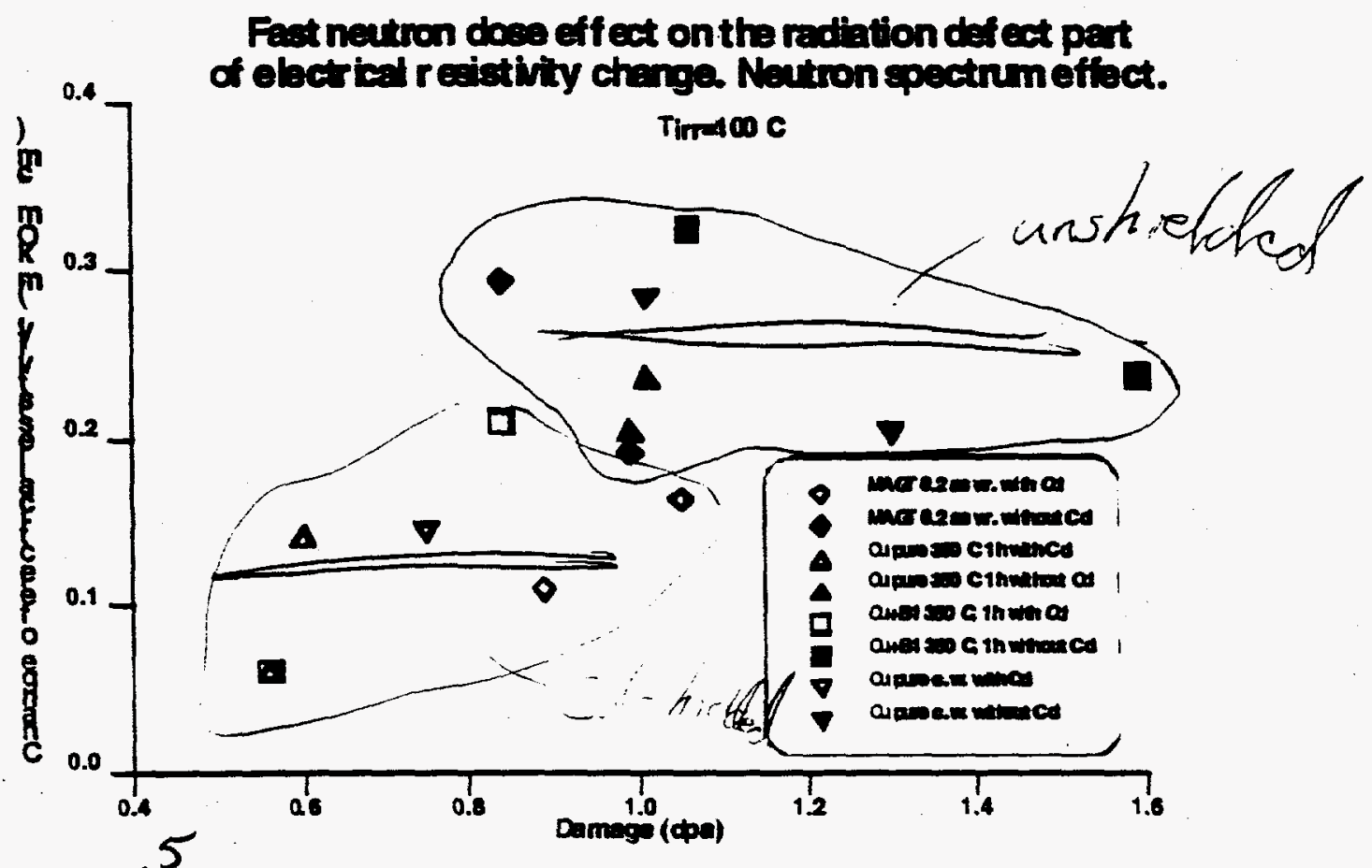

New Fig. (inciude additional data points; also encircle or shade groups of annealed and cw data)
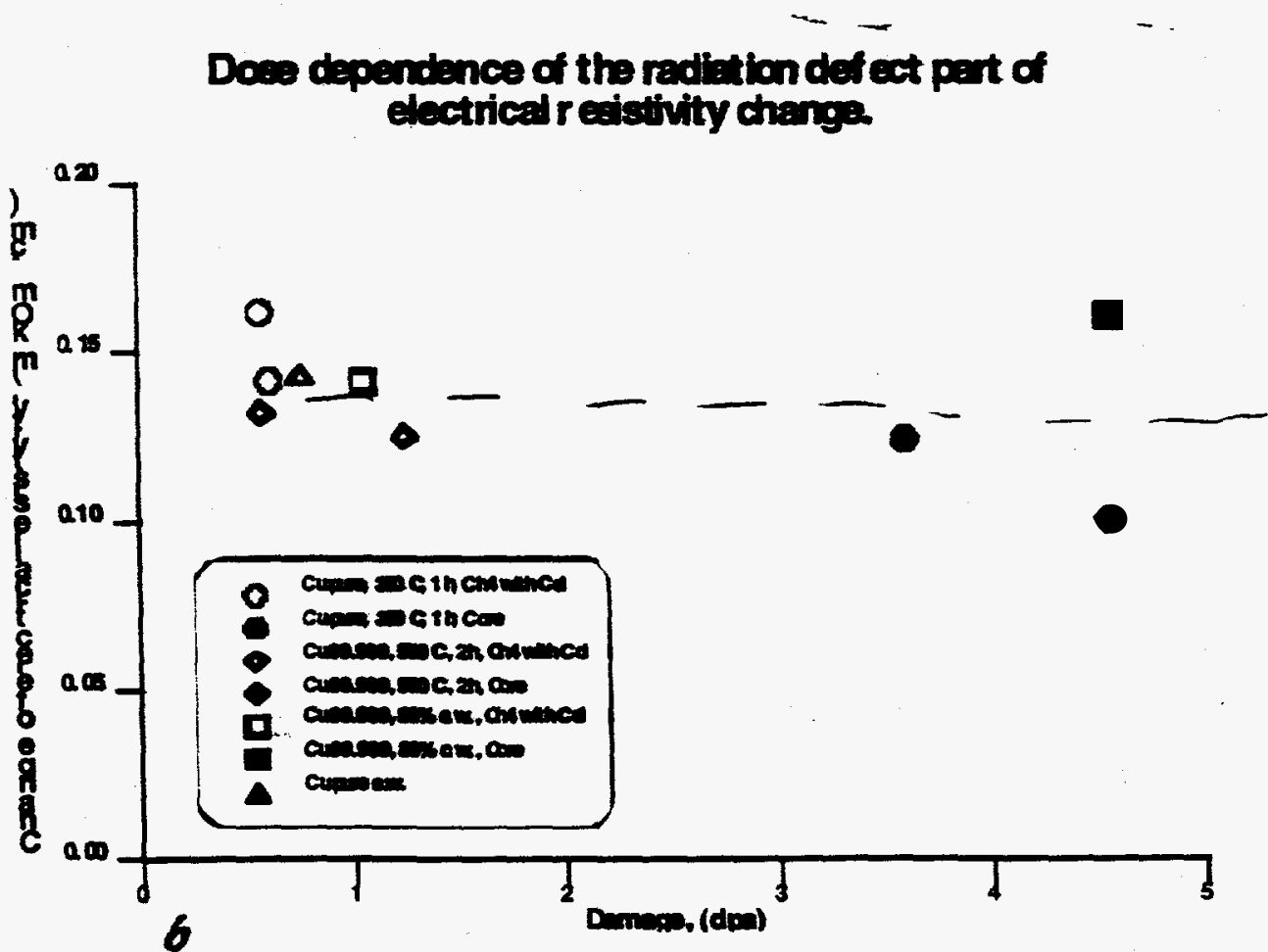

New Fig. $\$$ (change $\mathrm{Y}$-axis units to $\mathrm{n} \Omega-\mathrm{m}$ and add a horizontal dashed line through the data to help indicate that the resistivity change is independent of damage level; also add Tirr $100^{\circ} \mathrm{C}$ to figure) 


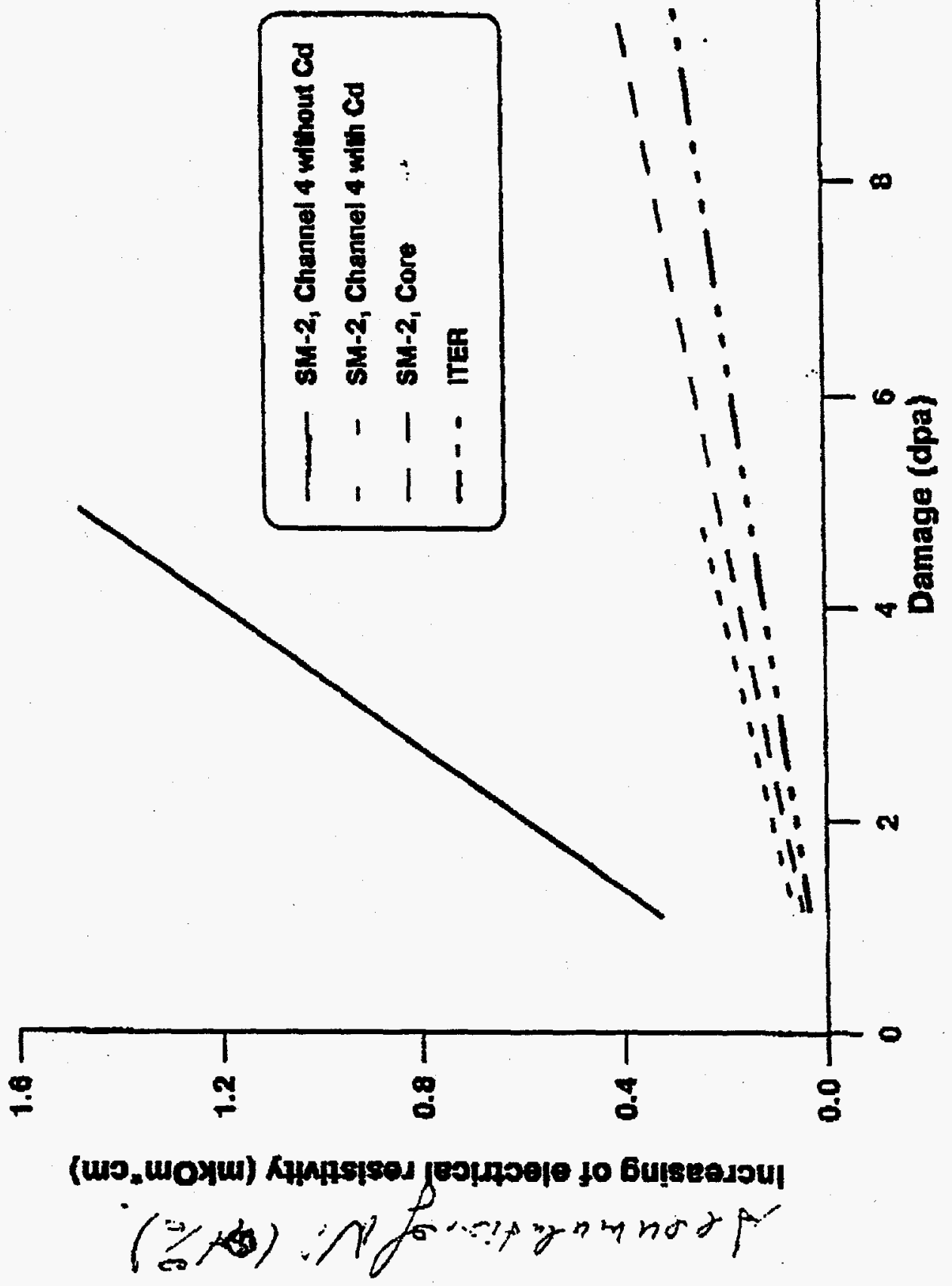

DISCLAIMER

This report was prepared as an account of work sponsored by an agency of the United States Government. Neither the United States Government nor any agency thereof, nor any of their employees, makes any warranty, express or implied, or assumes any legal liability or responsibility for the accuracy, completeness, or usefulness of any information, apparatus, product, or process disclosed, or represents that its use would not infringe privately owned rights. Reference herein to any specific commercial product, process, or service by trade name, trademark, manufacturer, or otherwise does not necessarily constitute or imply its endorsement, recommendation, or favoring by the United States Government or any agency thereof. The views and opinions of authors expressed herein do not necessarily state or reflect those of the 